\title{
ПАТОГЕНЕТИЧЕСКИЕ ОСОБЕННОСТИ ФИБРОГЕНЕЗА ПРИ ХРОНИЧЕСКИХ ЗАБОЛЕВАНИЯХ ПЕЧЕНИ
}

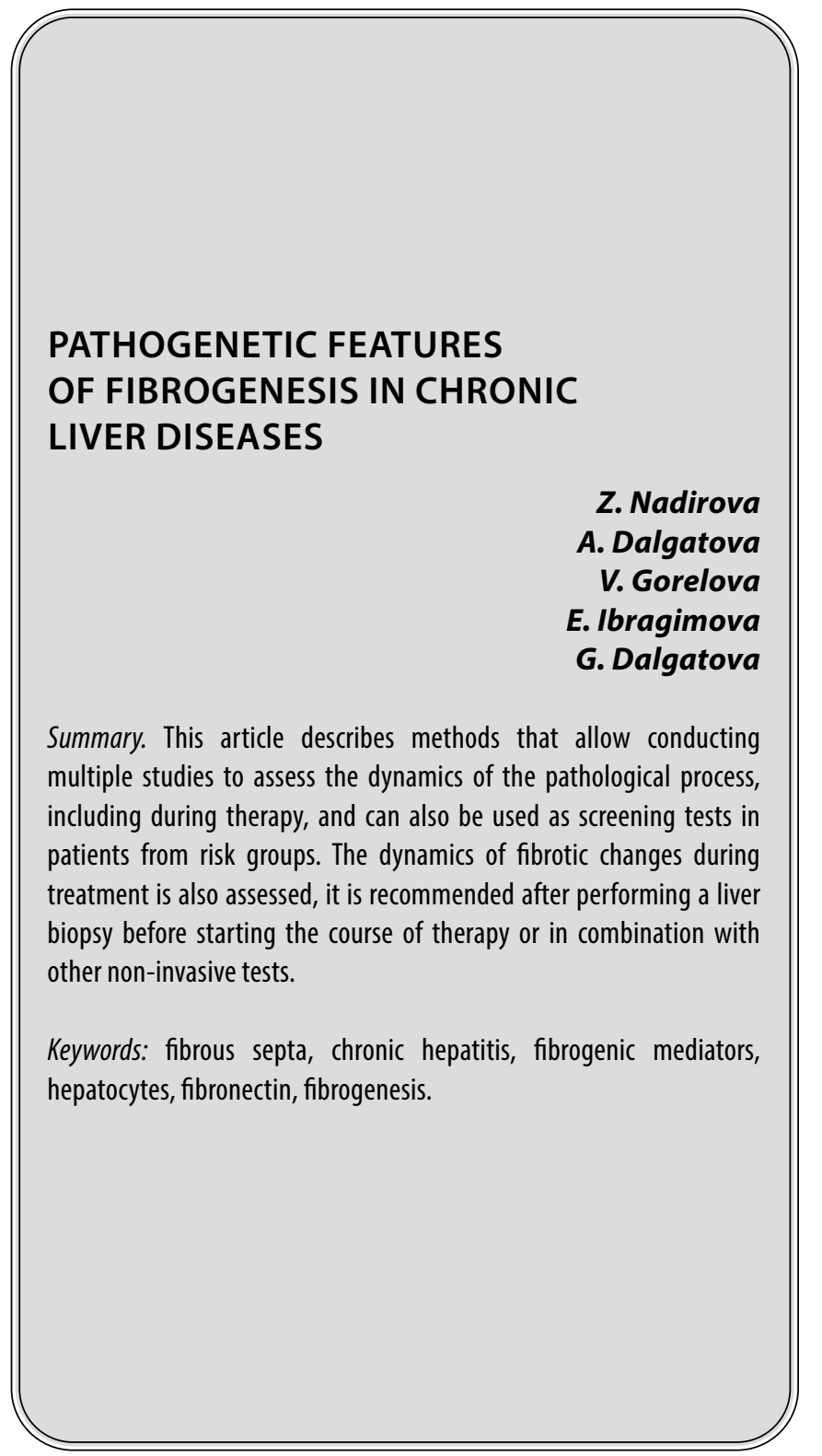

$\Phi$ иброз печени (ФП) - результат длительного ее повреждения, сопровождаемого диспозицией белков ВКМ, итог прогрессирования хронических заболеваний печени (ХЗП). Нарушение печеночной архитектоники с формированием фиброзных септ, узлов регенерации приводит, в конечном счете, к ЦП и нарушению печеночной функции [1].

Данное определение подразумевает, что ЦП - явление необратимое. Однако имеется достаточно до-
Надирова Зайнаб Абулмуслимовна

К.м.н., доцент, ФБГОУ ВО «Дагестанский государственный медицинский университет» МЗ РФ

zaynab_nadirova@mail.ru

Далгатова Асера Арабхановна

К.м.н., ассистент, ФБГОУ ВО «Дагестанский государственный медицинский университет» МЗ РФ

d.asera.a@mail.ru

Горелова Виктория Геннадьевна

К.м.н., доцент, ФБГОУ ВО «Дагестанский государственный медицинский университет» МЗ РФ

dgma@list.ru

Ибрагимова Эльмира Ибрагимовна

К.м.н., ассистент, ФБГОУ ВО «Дагестанский государственный медицинский университет» МЗ РФ

ibragim85@mail.ru

Далгатова Гюзель Арабхановна

К.м.н., ассистент, ФБГОУ ВО «Дагестанский государственный медицинский университет» МЗ РФ

d.guzel.a@mail.ru

Аннотация. В данной статье описываются методы, которые позволяют проводить многократные исследования для оценки динамики патологического процесса, в том числе и на фоне терапии, а также могут использоваться в качестве скрининг - тестов у пациентов из групп риска. Также оценивается динамика фиброзных изменений на фоне лечения рекомендовано после выполнения биопсии печени до начала курса терапии или в комплексе с другими неинвазивными тестами.

Ключевые слова: фиброзные септы, хронический гепатит, фиброгенные медиаторы, гепатоциты, фибронектин, фиброгенез.

казательств обратимости этого процесса. Основными причинами ФП у лиц, проживающих в индустриально развитых странах, являются хронический гепатит C (ХГ С), хронический гепатит В (ХГ В), злоупотребление алкоголем и неалкогольный стеатогепатит (НАСГ).

На ранних стадиях ФП практически никаких явных клинических проявлений этого патологического процесса не отмечается и лишь морфологическое исследование биоптата позволяет обнаружить признаки на- 
чинающихся структурных изменений, выражающихся в чрезмерном накоплении ВКМ. Молекулярный состав измененной соединительной ткани при ЦП примерно одинаков, независимо от этиологии процесса. Он считается результатом чрезмерного накопления ВKM. Естественное развитие хронического повреждения печени - прогрессирование фиброза, в конечном итоге приводящее к циррозу и гепатоцеллюлярной карциноме (ГЦК). Гепатоциты являются мишенями для большинства повреждающих агентов, включающих вирусы гепатита, метаболиты алкоголя, токсичные желчные кислоты и др. Повреждение гепатоцитов сопровождается высвобождением радикалов кислорода, фиброгенных медиаторов и активацией воспалительных клеTOK [2].

Среди факторов необратимого повреждения ткани печени выделяют местные и системные механизмы. В печени определенную роль играют следующие процессы:

- массовая гибель (некроз) гепатоцитов, которая нарушает, вызывая стрессорную (повреждающую) активацию синусоидальных клеток (СK), и прежде всего клеток Ито. В результате клетки Ито утрачивают пластические и регуляторные функции стволовых клеток и превращаются в зрелые фибробласты, которые не способны регулировать межклеточные взаимодействия и структуру ВКМ, вызывая дисбаланс функций клеток печени (потеря микроворсинок на гепатоцитах, капилляризация синусоидов, нарушение растормаживания митотических потенций гепатоцитов);

- преобладание процессов синтеза фибриллярных матриксных коллагенов и относительная недостаточность синтеза (активности) матриксных протеиназ (коллагеназ) ведет к формированию фиброзной ткани, которое начинается в пространстве Диссе. В результате имеет место отложение коллагена 1, 3, 5-го типов и фибронектина, которые создают препятствия для нормального обмена веществ между кровью синусоидов, гепатоцитов и СК [3].

- развитие дискоординации биорегуляторных ритмов активности гепатоцитов и СК вследствие снижения массы гепатоцитов до критического уровня. В результате резко возрастает функциональная нагрузка на эти клетки и, соответственно, снижается и десинхронизируется их митотическая активность, а также возрастает апоптоз сохранившихся гепатоцитов.

Многочисленные повреждающие агенты, являясь триггерами фиброгенеза, запускают процесс образования фибриллярных структур или чрезмерного синтеза и накопления ВКМ. Молекулярный состав измененной соединительной ткани при ФП примерно одинаков, независимо от этиологии процесса.

Длительная персистенция активных клеток Ито приводит к аккумуляции протеинов ВКМ и прогрессированию фиброза. Молекулы ВКМ объединяются в большие молекулярные образования: коллагены, неколлагеновые гликопротеиды, глюкозаминогликаны, протеогликаны и эластин. Накопление коллагена - важный этап развития ФП, так как он является основным компонентом, формирующим механический каркас органа [5].

Из 20 различных типов коллагена, имеющих определенную функцию и специфическую локализацию, более 10 найдено в печени. За формирование фибрилл отвечают коллагены I, III и IV типов, формирующие базальную мембрану клеток. После повреждения печени большое значение приобретают ранние изменения матрикса в пространстве Диссе, который из базального мембраноподобного матрикса начинает преобразовываться в интерстициальный матрикс, состоящий преимущественно из коллагена III и IV типов, входящего в состав фибрилл и фибронектина [6].

Подобное изменение состава ВКМ в конечном итоге может напрямую стимулировать фиброгенез. Коллаген IV типа, фибриноген и урокиназный тип активатора плазминогена активируют ЗК путем стимуляции латентных цитокинов, таких как TGF- $\beta 1$.

Фибриллярные коллагены могут связывать и стимулировать 3К посредством дискоидинового домена рецептора DDR2 и интегринов. Более того, измененный ВКМ может служить «резервуаром» для факторов роста (ФР) и ММП [215].

В результате избыточного синтеза компонентов ВКМ синусоиды превращаются в капилляры, исчезают фенестры эндотелия. В итоге нарушается обмен веществ между гепатоцитами и кровью. Стенозирование синусоидов повышает сосудистое сопротивление в печени и способствует формированию портальной гипертензии (ПГ) [7].

Прогрессирование фиброза нарушает архитектонику печени и обусловливает развитие ЦП и ПГ.

К тому же длительная стимуляция эпителиальной пролиферации в аномальной среде ВКМ (регенеративные узелки) предрасполагает к развитию ГЦК [6].

В процессе хронического воспаления увеличивается количество рецепторов к цитокинам, стимулирующих пролиферацию и фиброгенез. Активированные 
ЗК секретируют воспалительные хемокины, экспрессируют адгезивные молекулы и модулируют активацию лимфоцитов, особенно Т-хелперных клеток. Таким образом, создается замкнутый круг из иммунных клеток и клеток Ито, которые взаимно активируют друг друга. Радикалы кислорода и протеазы усиливают клеточное повреждение.

Любое повреждение гепатоцитов сопровождается высвобождением свободных радикалов и фиброгенных медиаторов, в том числе и цитокинов, вовлечением лейкоцитов в воспалительный процесс [6].

Кроме того, фиброгенную активность миофибробластов печени стимулирует апоптоз поврежденных гепатоцитов. Воспалительные клетки (лимфоциты, нормальные киллеры, полиморфно-ядерные клетки) активируют клетки Ито, синтезирующие коллаген. Они являются ключевыми в фиброгенезе печени.

Процесс регуляции ФП изучен недостаточно. Большинство результатов получено при исследовании на культуре 3К. В то же время понимание их роли in vivo осуществляется при изучении экспериментального фиброгенеза на лабораторных линиях мышей [7].

\section{Гены, регулируюшие}

Полиморфизм генов объясняет разное течение ФП при хронических заболеваниях печени. Однако результаты исследований данной проблемы крайне противоречивы и требуют дальнейшего изучения [85]. Многочисленные исследования, посвященные проблеме ФП, позволили определить ключевые гены, инициирующие фиброгенез [7].

Гены, регулирующие синтез воспалительных цитокинов (ИЛ-1, ИЛ-6, ИЛ-10, IFN- $\gamma$, остеопонтин), определяют развитие ФП в ответ на воспаление. Гены, кодирующие никотинамидадениндинуклеотидфосфат-Н-оксидазу (НАДФ-Н-оксидаза), регулируют как воспаление, так и депозицию ВКМ.

Данные ферментные системы сохраняют постоянную активность, продуцируя относительно низкие уровни свободнорадикальных веществ по отношению к базальным уровням и генерируют более высокие уровни перекисного окисления липидов (ПОЛ) в ответ на действие цитокинов. Регуляция синтеза фиброгенных факторов (TGF, FGF и др.), вазоактивных субстанций (ангиотензин-2, норэпинефрин) и адипокинов (лептин и адипонектин) способствует образованию компонентов ВКМ. Гены апоптоза клеток печени и (или) некроза (Bcl-xL, Fas-лиганды) влияют на степень повреждения гепатоцитов и последующий фиброзный ответ.
Кроме того, открыты специфические гены для каждого заболевания. Вариабельность генов, кодирующих воспалительные медиаторы (TNF- $\alpha$, ИЛ-1 $\beta$, ИЛ-10, цитотоксичный Т-лимфоцитарный антиген-4, рецептор CD14, супероксиддисмутаза), может способствовать прогрессированию алкогольной болезни печени, тогда как роль в фиброгенезе печени полиморфизма генов цитохрома Р-450, алкоголь - и альдегиддегидрогеназы, определяющих индивидуальную чувствительность к алкоголю, сомнительна.

Различные варианты ХГ С отвечают за персистенцию, противовирусный ответ, фиброгенные агонисты (ангиотензиноген, TGF- $\beta 1$ ), способствуют прогрессированию фиброза. Возможно, что ангиотензиноген и TGF- $\beta 1$ могут быть ассоциированы со степенью выраженности стеатоза.

«Золотым стандартом» оценки выраженности ФП остается биопсия печени. Однако в среднем лишь 5\% пациентам с риском развития фиброза проводят биопсию печени. Гистологическое исследование в ряде случаев позволяет уточнить причину заболевания печени, а также оценить степень активности. Наиболее распространенными и общепринятыми являются полуколичественные способы оценки выраженности ФП по шкале METAVIR или K.G. Ishak и соавт. [9]. Для морфометрического анализа могут использоваться специфические окраски, направленные на выявление компонентов ВКМ. К основным недостаткам биопсии печени относится инвазивный характер исследования, при котором боль наблюдается в $25 \%$ случаев, а у $0,5 \%$ больных - более серьезные осложнения. Их развитие нередко связано с опытом врача, выполняющего биопсию. Возможны ошибки при интерпретации гистологической картины различными исследователями или при повторном исследовании тем же специалистом. А также имеется масса несовершенств в имеющихся системах полуколичественной оценки стадии фиброза. Отмечается значительное различие показателей в различных образцах (до 40\%), высокая внутри - и межпатологическая вариабельность [4].

Существует ряд противопоказаний к проведению биопсии печени: коагулопатии; повышенное давление в желчных путях; аллергические реакции на обезболивающие препараты; негативный настрой и страх пациента; нежелательность наркоза для бывших потребителей психоактивных веществ; отягощённость другими заболеваниями, особенно в пожилом возрасте.

Кроме того, высокая стоимость и нежелание больных подвергаться инвазивным процедурам обусловливают необходимость разработки неинвазивных методов диагностики фиброза печени. 
Учитывая необходимость в простом неинвазивном и воспроизводимом методе оценки ФП, современный этап развития клинической гепатологии характеризуется постепенным отходом от традиционно принятого, служившего в течение веков основным путем накопления врачебных знаний, морфологического метода исследования. Этому способствуют три обстоятельства: бурное развитие методов визуализации, позволяющих получить детальную картину структуры органа; высокая стоимость биопсии и морфологического исследования ткани печени в западных странах; пассивная позиция гепатологов, не владеющих методикой забора ткани печени и не умеющих трактовать результаты морфологического исследования. Основной аргумент - инвазивность биопсии - часто служит поводом для необоснованного отказа от проведения морфологического исследования, результаты которого в сложных клинических ситуациях становятся определяющими в подтверждении диагноза и определении стратегии терапии хронического заболевания печени. Аналогичный подход в европейских странах, в частности во Франции, послужил стимулом для поиска и разработки неинвазивных методов (эластометрия - изучение эластических свойств ткани печени; сывороточные тесты - определение компонентов экстрацеллюлярного матрикса, принимающих участие в процессе фиброгенеза, в сыворотке крови), диагностики фиброза печени у больных хроническими гепатитами, значительно сузив при этом спектр показаний к биопсии печени.

Предложено несколько способов оценки выраженности ФП на основании рутинных лабораторных тестов, включающих показатели активности аминотрансфераз и белков острой фазы воспаления в сыворотке крови, количества тромбоцитов, протромбинового времени.

Содержание в сыворотке белков, непосредственно связанных с фиброгенезом в печени, таких как N-концевой пропептид коллагена III типа, а также гиалуроновую кислоту, тканевой ингибитор металлопротеиназ 1 типа также пытаются использовать в качестве суррогатных маркеров ФП [3]. Эти подходы к оценке ФП обладают высокой специфичностью при крайних степенях выраженности фиброза: ЦП или минимальных изменений в печени, но недостаточно специфичны для разграничения промежуточных вариантов.

Специфичные для фиброза белки могут отражать фиброгенез в других органах (например, фиброз поджелудочной железы у больных с хронической алкогольной интоксикацией). В стадии разработки находятся методы неинвазивной диагностики фиброза, основанные на протеомике и гликомике сывороточных белков, с использованием анализаторов последова- тельностей/фрагментов ДНК, способных генерировать профили $\mathrm{N}$-протеингликанов сыворотки крови.

Наконец, ФП пытаются оценить при помощи лучевых, т.е. визуальных методов диагностики. Ультразвуковое исследование, компьютерная и магнитно-резонансная томографии позволяют выявлять изменения паренхимы печени, обусловленные значительным и тяжелым фиброзом. Ультразвуковое исследование позволяет выявлять продвинутые стадии ЦП на основании обнаружения неровного контура печени, признаков портальной гипертензии [6]. Оценка данных ультразвукового исследования в значительной степени зависят от профессионализма врача, проводящего данную манипуляцию. Кроме того, повышенная эхогенность печени может наблюдаться не только при выраженном фиброзе, но и при значительном стеатозе печени.

Наконец, обнадеживает внедрение в клиническую практику кратковременной эластографии печени («ФиброСкан») [6].

В то же время необходимо помнить, что клиническое применение неинвазивной диагностики фиброза (эластометрии и сывороточных тестов) стало возможным после сравнительного анализа получаемых данных с результатами морфологического исследования ткани печени.

Вышеперечисленные обстоятельства объясняли назревшую необходимость в разработке и внедрении в практику точных, информативных и неинвазивных методов диагностики фиброза печени на любой стадии процесса. Требовались методы, которые позволили бы проводить многократные исследования для оценки динамики патологического процесса, в том числе и на фоне терапии, а также могли бы использоваться в качестве скрининг - тестов у пациентов из групп риска.

Одним из таких высокотехнологичных неинвазивных методов оценки степени фиброза печени является фиброэластометрия - определение фиброза с помощью упругих волн. Исследование проводится на аппарате «Фиброскан» (Echosens, Франция; рис 1). Фиброскан был изобретен и сконструирован во Франции в начале 2000-х. В серийное производство поступил в 2003 году, а в России прошел государственную регистрацию в конце 2006 года. Теоретической предпосылкой для разработки эластометрии послужил клинический опыт расшифровки уплотнения печени при пальпации в пользу выраженного ФП или ЦП. Выделяют 4 этапа в совершенствовании эластографической техники:

1 - статическая эластография;

2 - динамическая эластография; 


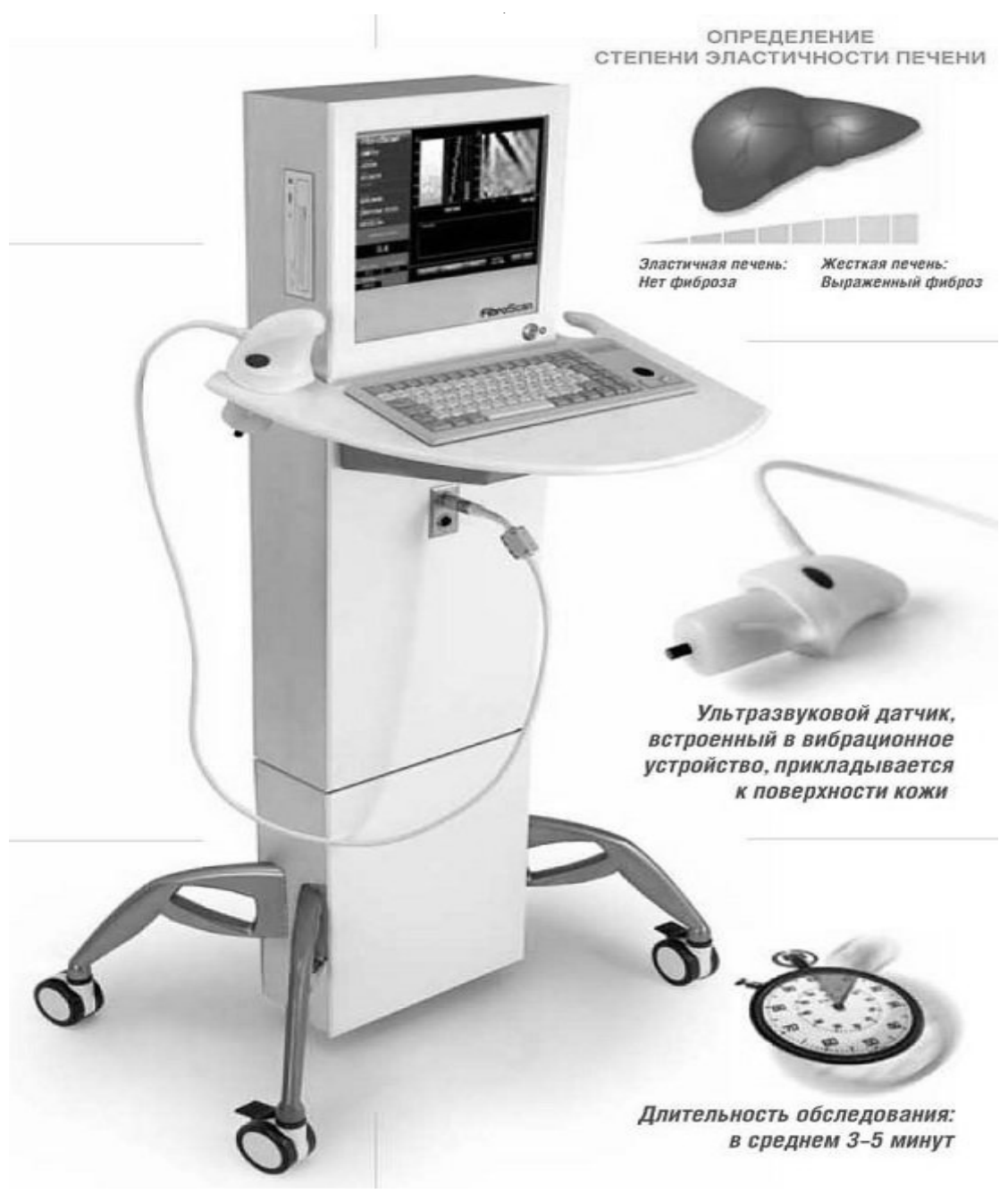

Рис. 1. Аппарат «Фиброскан»

3 - дистанционная эластография;

4 - кратковременная эластография (транзиторная), наиболее приемлемая для оценки выраженности ФП.

Рабочая часть аппарата представлена ультразвуковым преобразовательным датчиком, в который установлен источник колебаний средней амплитуды и низкой частоты. Генерируемые им колебания передаются на исследуемые подлежащие ткани печени и создают упругие волны, подвергающие модуляции отраженный ультразвук. Скорость распространения упругих волн определяется эластичностью печеночной ткани, которая в свою очередь зависит от содержания в печени фиброзной ткани. Полученный результат выражается в килопаскалях (кПа) и позволяет четко распределять больных по стадиям заболевания от F0 (отсутствие фиброза) до F4 (цирроз печени) по шкале METAVIR.

Многочисленные исследования подтвердили достаточно высокую степень соответствия стадии фиброза, полученную в результате фиброэластометрии и данным системы полуколичественной оценки фиброза по METAVIR на основании морфологических изменений в биоптатах (табл. 2) при максимальной диагностической точности эластометрии при стадиях F3-F4 [3]. Kpoме того, показана отличная прогностическая ценность фиброэластометрии, высокая чувствительность и специфичность метода [43].

Суммарный объем подвергающейся исследованию печеночной ткани составляет в среднем 6 см3, что многократно превышает таковой при пункционной биопсии и позволяет судить о состоянии печени в целом, а не отдельного её фрагмента.

Преимущества метода заключаются в следующем: метод безопасен; нетравматичен; используется в педиатрии; проводится без предварительного обследования и подготовки пациента; не требует госпитализации; экономически доступнее, чем процедура биопсии; по- 
зволяет осуществлять диагностику цирроза на ранних стадиях; не требует наличия в медицинском учреждении опытного морфолога; может повторяться пациенту неоднократно, что актуально при диспансерном наблюдении и контроле эффективности лечения.

Процедура безболезненна и занимает несколько минут. Результаты отображаются на мониторе и заносятся в электронную базу данных пациентов. Специаль- ной подготовки к процедуре не требуется. Исследование производится в положении пациента лежа на спине с максимальным отведением правой руки. Никаких неприятных ощущений исследование не вызывает.

В Дагестане впервые на Северном Кавказе с февраля 2010 г. на базе медицинского центра «Гепар» г. Махачкала успешно внедрена в практику фиброэластометрия с использованием аппарата «Фиброскан».

\section{ЛИТЕРАТУРА}

1. Ивашкин В.Т., Воликовский Л.Я., Тесаева Е.В. Первый российский опыт неинвазивной диагностики фиброза печени с помощью аппарата «ФиброСкан» // Российский журнал гастроэнтерологии и гепатологии. 2006. № 6. С. 65-69.

2. Калашникова М.М. Ультраструктурная характеристика процесса резорбции коллагена в цирротически измененной печени // Бюллетень экспериментальной биологии. 2000. Т. 129, № 1. С. 4-11.

3. Морозов С.В., Труфанова Ю.М., Павлова Т.В. и др. Применение эластографии для определения выраженности фиброза печени: результаты регистрационного исследования в России // Экспериментальная и клиническая гастроэнтерология. 2008. № 2. С. 40-47.

4. Павлов, Ч.С. Фиброз печени при хронических вирусных гепатитах В и С: дис... д-ра мед. наук. М., 2009. 252 с.

5. Павлов Ч.С., Глушенков Д.В., Ивашкин В.Т. Современные возможности эластометрии, фибро- и акти-теста в диагностике фиброза печени // Российский журнал гастроэнтерологии, гепатологии и колопроктологии. 2008. T. XVIII, № 4. С. 43-52.

6. Глушенков Д.В., Коновалова 0.Н., Ивашкин В.Т. и др. Неинвазивная диагностика фиброза печени на ранних стадиях его развития // Российский журнал гастроэнтерологии, гепатологии, колопроктологии. (Приложение № 32). 2008. Т. 18, № 5. С. 83.

7. Глушенков Д.В., Павлов Ч.С., Маевская М.В., Ивашкин В.Т. и др. Возможности эластометрии и фибротеста в диагностике цирроза печени // Российский журнал гастроэнтерологии, гепатологии, колопроктологии. (Приложение № 31). 2008. Т. 18, № 1. С. 9.

8. Afdhal N.H., Nunes D. Evaluation of liver fibrosis: a concise review // Am.J. Gastroenterol. 2004. V. 99. P. 1160-1174.

9. Desmet V.J. Milestones in liver disease. Scoring chronic hepatitis // J. Hepatol. 2003. V. 38. P. 382-386.

( ) Надирова Зайнаб Абулмуслимовна (zaynab_nadirova@mail.ru ), Далгатова Асера Арабхановна ( d.asera.a@mail.ru ), Горелова Виктория Геннадьевна ( dgma@list.ru ),Ибрагимова Эльмира Ибрагимовна ( ibragim85@mail.ru ), Далгатова Гюзель Арабхановна ( d.guzel.a@mail.ru ). 